\title{
Effect of Food on the Bioavailability of Prednisone
}

\author{
AUbrey V. TeMBO, Ph.D., ERMELINDA SAKMAR, B.S., MARGARETte R. HALLMARK, M.A., \\ DONAld J. WEIDLER, M.D., Ph.D., and JOHN G. WAGNeR, Ph.D. Ann Arbor, Mich.
}

$P^{2}$ REDNISONE is a potent adrenocortical steroid that is offered for the palliative treatment of rheumatoid arthritis and disorders of many organs. The antiinflammatory response due to prednisone is generally observed within the first 24 to 48 hours. Previous studies ${ }^{1-6}$ have shown that the rate of appearance of prednisone and the metabolite prednisolone, as well as clinical effectiveness of the drug, correlate with the in vitro dissolution rate of prednisone from commercial tablets. Partly because of the low solubility of the drug in aqueous media, prednisone was listed as one of the drugs susceptible to bioavailability problems. ${ }^{7}$ DiSanto and DiSante ${ }^{8}$ also discussed bioavailability and pharmacokinetics of prednisone. To our knowledge, no studies have attempted to assess the bioavailability of prednisone in the presence of food, even though the drug is often administered in situations where food intake is not regulated. Food is known to decrease the rate of absorption of many drugs and, sometimes, to decrease the per cent of the dose of drug that is ultimately absorbed. ${ }^{9}$ In rare cases, food

From the College of Pharmacy and the Upjohn Center for Clinical Pharmacology, The University of Michigan, Ann Arbor, Mich. 48109. These studies were performed pursuant to Contract 223-75-3033 with DHEW/Public Health Service, Food and Drug Administration, Rockville, Md., and were partly supported by Public Health Service Grant 5-P11-GM15559. has been shown to increase the efficiency of absorption of a drug. ${ }^{10-12}$

This article reports the results of a four-treatment crossover study in which two different commercially available tablets of prednisone were given under fasting and nonfasting conditions. These tablets were the slowest and fastest dissolving tablets both in vitro and in vivo of eight different prednisone tablets tested by Sullivan et al. ${ }^{6}$ The objectives of the study were (a) to determine whether food decreases, increases, or has no effect on the absorption of prednisone; and (b) whether the effect of food is greater or smaller with a tablet that releases its contained prednisone slowly or rapidly.

\section{Methods}

Four healthy adult male volunteers between the ages of 23 and 28 years and weighing 80 to $91 \mathrm{~kg}$ were selected. The criteria for subject selection utilized in these laboratories have been previously reported. ${ }^{13}$ During each phase of the crossover, each subject ingested $10 \mathrm{mg}$ prednisone as two 5-mg tablets of either tablet A or B. (Tablet A was C. T. prednisone, $5 \mathrm{mg}$, Danbury Pharmacal Inc., I ot No. 4539; tablet B was C. T. Meticorten, Schering Corp., Lot No. 2ABB804.) A crossover experimental design was followed, allowing a one-week interval

The Journal of Clinical Pharmacology 
BIOAVAILABILITY OF PREDNISONE

TABLE I

Treatment Schedule*

\begin{tabular}{ccccc}
\hline $\begin{array}{c}\text { Subject } \\
\text { no. }\end{array}$ & Week 1 & Week 2 & Week 3 & Week 4 \\
\hline 1 & AF & BF & BE & AE \\
2 & BF & AE & AF & BE \\
3 & AE & BE & BF & AF \\
4 & BE & AF & AE & BF \\
\hline
\end{tabular}

* $\mathrm{AF}=$ Danbury tablet given under fasting state; $\mathrm{BF}=$ Schering tablet given under fasting state; $\mathbf{A E}=$ Danbury tablet given immediately following heavy breakfast; $\mathrm{BE}=$ Schering given immediately following a heavy breakfast.

between treatments. The treatment schedule used is shown in Table $I$.

On the evening before each treatment period, $1.0 \mathrm{mg}$ dexamethasone was administered orally at 11:00 P.M. to each subject to suppress endogenous secretion of cortisol. The suppression was maintained by administration of $0.5 \mathrm{mg}$ dexamethasone 8 hours after the administration of prednisone. Dexamethasone does not interfere with the radioimmunoassay for prednisolone.

In all studies the subjects were required to fast overnight from 10 P.M. the night before prednisone administration. Within the first hour after arising in the morning, each subject drank $8 \mathrm{fl}$ oz tap water. Immediately before prednisone administration, at time zero, $10 \mathrm{ml}$ whole blood was taken from the forearm vein of each subject and plasma was harvested. One milliliter of this zero-hour plasma was diluted either 1:10 or 1:50 (depending upon dilution of future unknown plasmas) with water, and 1-ml aliquots of this diluted plasma were spiked with $0,0.4$, $0.8,2,4,6$, and $10 \mathrm{ng}$ prednisolone for the calibration curve. The drug was ingested with the aid of $6 \mathrm{fl} \mathrm{oz}$ tap water (fasting treatments) or immediately following a breakfast of two eggs, two slices of ham, two slices of buttered toast, and a cup of coffee with cream and sugar (nonfasting treatments). Subsequently, $10 \mathrm{ml}$ whole blood was taken at $0.25,0.5,1,2,3,4,6,8$, 12 , and 24 hours after dosing with prednisone. Each sample was centrifuged as soon as possible after collection; the plama was placed in stoppered vials, quick-frozen $\left(-20^{\circ} \mathrm{C}\right)$, and kept frozen until just before assay.

The subjects were not permitted food or beverage until 4 hours after prednisone administration. Four hours after dosing with prednisone, food and beverages were allowed ad libitum. All samples were analyzed for prednisolone by the modification of Sullivan et al. ${ }^{13}$ of the radioimmunoassay of Colburn and Buller.4 Plasma concentrations of prednisolone were calculated by inverse estimation using parameters of the least-squares line for a logistic-logarithmic plot. In this type of plot, $\ln [100\{100-B(X) / B(0) / B(X) /$ $B(0)\}$ ] is plotted versus $\ln C$, where $\ln$ stands for natural logarithm, $B(0)$ is the per cent bound in the absence of prednisolone, $B(X)$ is the per cent bound at the concentration $C$, and $C$ is the concentration of prednisolone $(\mathrm{ng} / \mathrm{ml})$ of plasma.

\section{Results}

Table II and Figure 1 summarize the mean plasma concentrations of prednisolone. The coefficients of variation of 
TEMBO, SAKMAR, HALLMARK, ET AL.

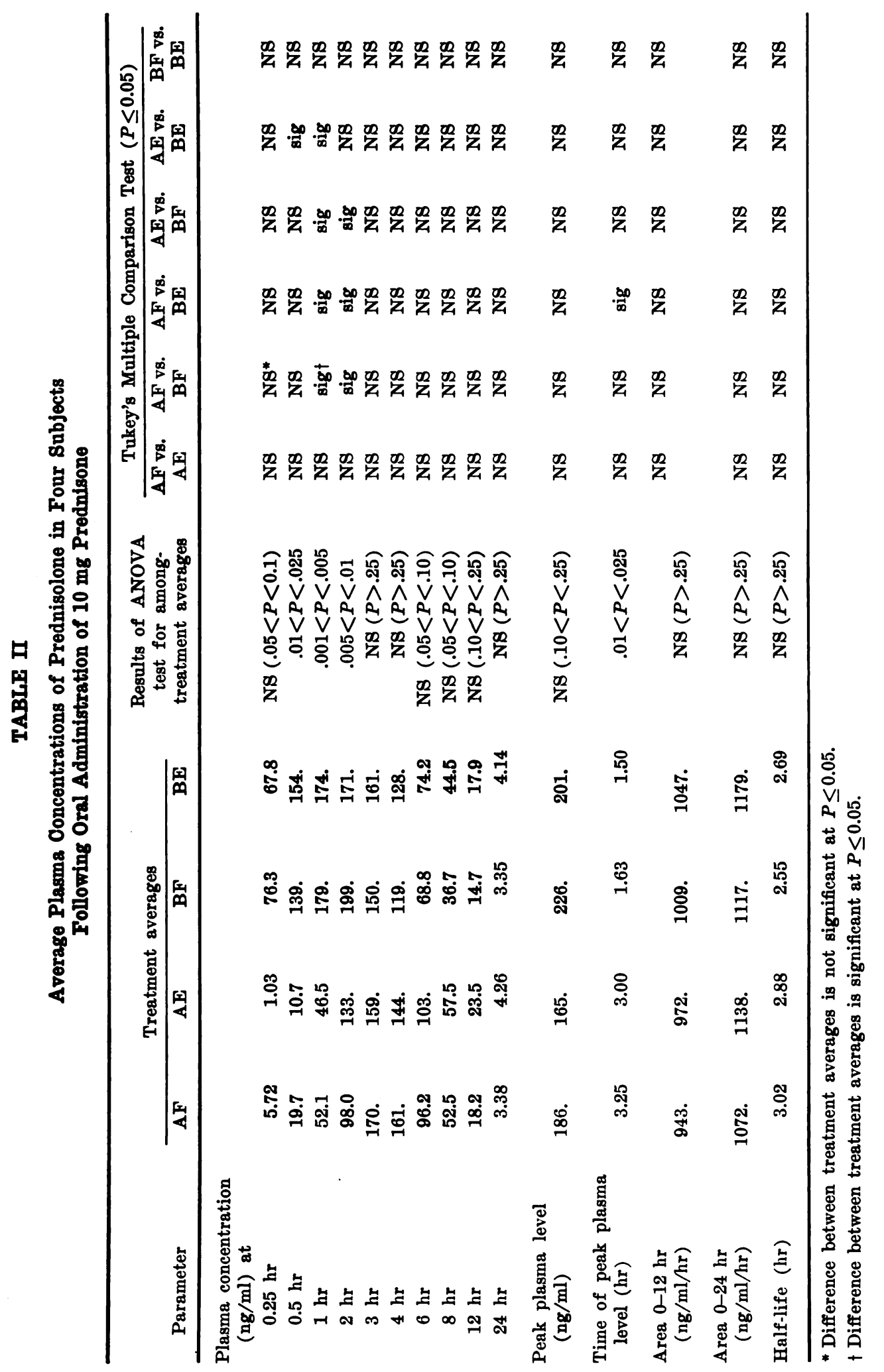




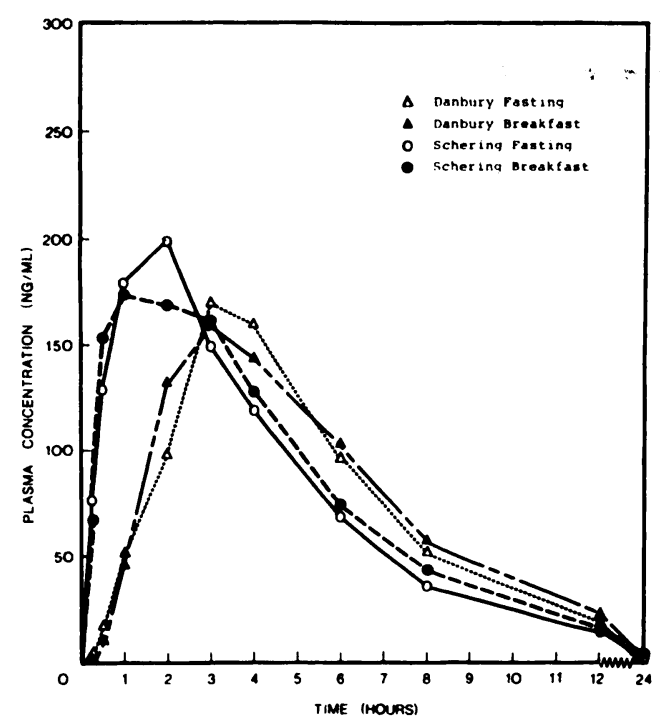

Fig. 1. Average plasma concentrations of prednisolone after oral administration of 10 mg prednisone tablet $A$ to fasting $(\Delta)$ and nonfasting ( $\triangle$ ) subjects, and $10 \mathrm{mg}$ prednisone tablet $B$ to fasting (O) and nonfasting (•) subjects. the means given in Table II are presented in Table III. Table II also lists results of analyses of variance (ANOVA) for crossover design and results of Tukey's ${ }^{18}$ multiple comparison

\section{Discussion}

The mean plasma prednisolone concentrations observed under fasting conditions with tablets $A$ and $B$ in this study were very similar to those reported formerly with the same tablets by Sullivan et al. ${ }^{6}$ Results of Tukey's tests, ${ }^{16}$ shown in Table II, indicate that the treatment means of $\mathrm{AF}$ and $\mathrm{AE}$, and also of $\mathrm{BF}$ and $\mathrm{BE}$, do not differ significantly $(P>0.05)$. Hence, the differences observed are attributable to differences in the release of prednisone from the two different commercial tablets and not to the effect of food versus fasting on either tablet.

It is interesting to note that in two of

\section{TABLE III}

Coefficients of Variation of Average Plasma Concentration of Prednisolone Given in Table II

\begin{tabular}{lcccc}
\hline & \multicolumn{4}{c}{$\begin{array}{c}\text { Coefficient of variation (\%) } \\
\text { for treatment }\end{array}$} \\
\cline { 2 - 5 } Parameter & AF & AE & BF & BE \\
\hline Plasma concentration (ng/ml) at & & & \\
$0.25 \mathrm{hr}$ & 70.9 & 164. & 119. & 85.5 \\
$0.5 \mathrm{hr}$ & 51.5 & 157. & 79.2 & 46.1 \\
$1 \mathrm{hr}$ & 83.4 & 113. & 26.6 & 39.6 \\
$2 \mathrm{hr}$ & 59.6 & 38.6 & 14.7 & 8.70 \\
$3 \mathrm{hr}$ & 16.4 & 26.1 & 22.8 & 13.0 \\
$4 \mathrm{hr}$ & 12.5 & 17.3 & 33.8 & 24.3 \\
$6 \mathrm{hr}$ & 18.8 & 12.2 & 31.0 & 17.2 \\
$8 \mathrm{hr}$ & 23.3 & 14.5 & 31.4 & 34.2 \\
$12 \mathrm{hr}$ & 38.5 & 17.5 & 27.0 & 34.5 \\
$24 \mathrm{hr}$ & 74.7 & 58.8 & 72.1 & 97.0 \\
Peak plasma level (ng/ml) & 7.5 & 20.1 & 25.5 & 14.6 \\
Time of peak plasma level (hr) & 29.5 & 27.2 & 46.2 & 66.7 \\
Area $0-12 \mathrm{hr}(\mathrm{ng} / \mathrm{ml} / \mathrm{hr})$ & 15.9 & 14.8 & 24.6 & 5.97 \\
Area $0-24 \mathrm{hr}(\mathrm{ng} / \mathrm{ml} / \mathrm{hr})$ & 18.3 & 13.7 & 24.6 & 6.20 \\
Half-life (hr) & 27.2 & 6.7 & 14.8 & 26.2 \\
\hline
\end{tabular}


the subjects the presence of food in the gastrointestinal tract produced lower peak plasma concentrations of prednisolone than under fasting conditions. In one subject, food appeared to increase slightly the peak plasma concentration of prednisolone compared with fasting conditions. In the fourth subject, food appeared to have no effect on peak plasma prednisolone concentration.

\section{Bummary}

Two commercial prednisone tablets were studied which had previously been shown by Sullivan et al. ${ }^{5,6}$ to have the slowest and fastest in vitro rates of dissolution, and the slowest and fastest rise to peak plasma prednisolone concentrations in human beings. The effect of food on the absorption of these two tablets was studied in a crossover study, which also repeated the fasting conditions used by Sullivan et al. ${ }^{6}$ Marked differences in mean prednisolone plasma concentrations during the 0- to 2-hour absorption phase were observed between the two tablets again, but food did not affect either tablet with respect to mean plasma prednisolone concentrations.

\section{References}

1. Campagna, F. A., Cureton, G., Mirigian, R. A., and Nelson, E.: Inactive prednisone tablets USP XVI. J. Pharm. Sci. 52:005 (1968).

2. Levy, G., Hall, N. A., and Nelson, E.: Studies on inactive prednisone tablets USP XVI. Amer. J. Hosp. Pharm. 21:402 (1964).

3. Wagner, J. G.: Bioavailability and generic equivalency. In The Scientific Evaluation of Drug Equivalency, Proceedings of a Colloquium, Washington, D.C., June 14, 1974, Excerpta Medica, pp. 79-86.
4. Sullivan, T. J., Sakmar, E., Albert, K. S., Blair, D. C., and Wagner, J. G.: In vitro and in vivo availability of commercial prednisone tablets. J. Pharm. Sci. 64:1723 (1975).

5. Sullivan, T. J., Sakmar, E., and Wagner, J. G.: Comparative bioavailability: a new type of in vitro-in vivo correlation exemplified by prednisone. J. Pharmacokin. Biopharm. 4:173 (1976).

6. Sullivan, T. J., Hallmark, M. R., Sakmar, E., Weidler, D. J., and Wagner, J. G.: Comparative bioavailability: eight commercial prednisone tablets. J. Pharmacokin. Biopharm. 4:157 (1976).

7. An annotated list of drugs with potential for therapeutic inequivalence based on current evidence of drug product bioavailability inequivalence. J. Amer. Pharm. Assoc. N8 13:279 (1972).

8. DiSanto, A. R., and DeSante, K. A.: Bioavailability and pharmacokinetics of prednisone in humans. J. Pharm. Sci. 64:109 (1975).

9. Wagner, J. G.: Fundamentals of Clinical Pharmacokinetics. Hamilton, IIl., Drug Intelligence Publication, 1975, p. 393.

10. Bates, T. K., Sequeira, J. A., and Tembo, A. V.: Fffect of food on nitrofurantoin absorption. Clin. Pharmacol. Therap. 16: 63 (1974).

11. Levy, G., and Jusko, W. J.: Factors affecting the absorption of riboflavin in man. J. Pharm. Sci. 55:285 (1966).

12. Crounse, R. G.: Effective use of griseofulvin. Arch. Dermatol. 87:176 (1963).

13. Sullivan, T. J., Stoll, R. G., Sakmar, E., Blair, D. C., and Wagner, J. G.: In vitro and in vivo availability of some commercial prednisolone tablets. J. Pharmacokin. Biopharm. 2:29 (1974)

14. Colburn, W. A., and Buller, R. H.: Radioimmunoassay for prednisolone. Steroids $21: 833$ (1973).

15. Tembo, A. V., Schork, A. M., and Wagner, J. G.: Statistical survey of saturation analysis calibration curve data for prednisolone, prednisone and digoxin. Steroids, in press.

16. Tukey, J. W.: Comparing individual means in the analysis of variance. Biometrics 5 : 99 (1949).

Address reprint requests to: Dr. John G. Wagner, Upjohn Center for Clinical Pharmacology, The University of Michigan, Ann Arbor, Mich. 48109. 